\title{
VERSITA
}

10.2478/v10284-012-0003-1

\section{ETHICS OF DOWNSIZING}

\section{OLGA OSIPOVA}

\section{INTRODUCTION - THE PHENOMENON OF DOWNSIZING}

The phenomenon of downsizing first appeared in the mid $20^{\text {th }}$ century in the United States. What were the forces that drove the US firms for the need of re-evaluating their organisational structures, one of the results of which were mass layoffs? One of the strongest forces is perhaps the economic shift of the 1980s, when much of the assumptions about the organisation have been re-evaluated and changed. The economic boom, particularly the fast industrial development added with the technological progress and processes of globalisation and de-regulation, placed large international businesses in a tough competitive environment. Therefore, businesses started to look for new organisational structures (a shift from tall bureaucratic structure to a flat one) and new leadership approaches. This shift demanded major cost cutting; therefore, for this reason, many US organisations turned to downsizing as a survival strategy.

Downsizing can be defined as "a set of activities ... undertaken on the part of management, designed to improve organizational efficiency, productivity, and/or competitiveness. It represents a strategy that affects the size of the firm's workforce and its work processes"(Huber er Glick, 1993). Therefore, from the management point of view, downsizing is referred to as a strategy or a management tool as a way of re-engineering and rightsizing.

Downsizing or rather 'rightsizing' affected nearly every economic sector such as air transportation, banking and finance, pharmaceutical industry, information technologies, etc. For example, in 1998 Boeing (Aerospace, USA) laid off as much as 20,000 workers, following with 28,000 more in 1999. This is approximately a 10\% cut from the total number of employees (Freeman, 1998). Over the course of four years, Boeing had decreased its number of employees from 238,600 in 1998 to 187,000 in 2001, which is more than 20\% of terminated workers (Boeing employment table, 2012). One of the major reasons for downsizing was Boeing's merger with McDonnell Douglas in 1997 as a prevention of duplication of work and optimising resources. However, during early 1998, Boeing experienced problems with meeting its operational plan, one of the causes of which was that the company let go many skilled workers and the existing workforce was not able to handle the workload (Freeman, 1998). 
The study by Clark er Koonce (1995) revealed that 68\% of the companies that downsized in the 1990s did not experience an increase in profits during that period. It also showed that a majority of these companies failed to report any improvements in productivity. This has led to major criticism of downsizing coupled with the fact that senior executives salaries had increased by over 1000\% between 1980 and 1995, while the percentage of layoffs continued to increase (Case studies and Management resources, 2002). Despite of all these, announcements on downsizing are taken positively by Wall Street, because downsizing is viewed as a way of cost savings, thus higher returns (Cole, 1995). The danger of this is that many companies may see downsizing as a tool for increasing their financial value and apply rightsizing as 'me-too' strategy, even if it is not necessary.

The study conducted by Hickok (1995) examined the problems of downsizing from a psychological point of view. Hickok observed a major change in organisational culture after downsizing: a shift from the welfare of an individual to the welfare of the organisation as a whole; from familial working relationships to being competitive; from viewing an employer as a long-term and stable to short-term and contingent.

By briefly looking at the downsizing phenomenon and some of its causes and implications, it is clear that this is an extremely controversial issue, which creates an ethical dilemma. Is 'rightsizing' always justified or is it often led by corporate greed? Is it indeed an effective management tool that benefits the organisations? Is downsizing unethical or is it the only solution for a company to remain competitive in tough economic conditions? I shall try to answer these and many other questions in further sections of this paper.

In the second section - Downsizing: Identifying Moral Issues and Moral Principles, I will look at the notion of downsizing, taking a real case study of layoffs in Boeing Corporation (1971 ev 1997), and try to determine the possible motives for these layoffs. Each of the reasons creates moral issues or ethical dilemmas in a sense that they have numerous effects on stakeholders that are often in conflict with each other (employees, shareholders, people in the community, etc). I will then discuss these moral issues in the context of moral principles and talk about possible limitations of the applied principles.

In general, my arguments shall be following the diagram outlined below:

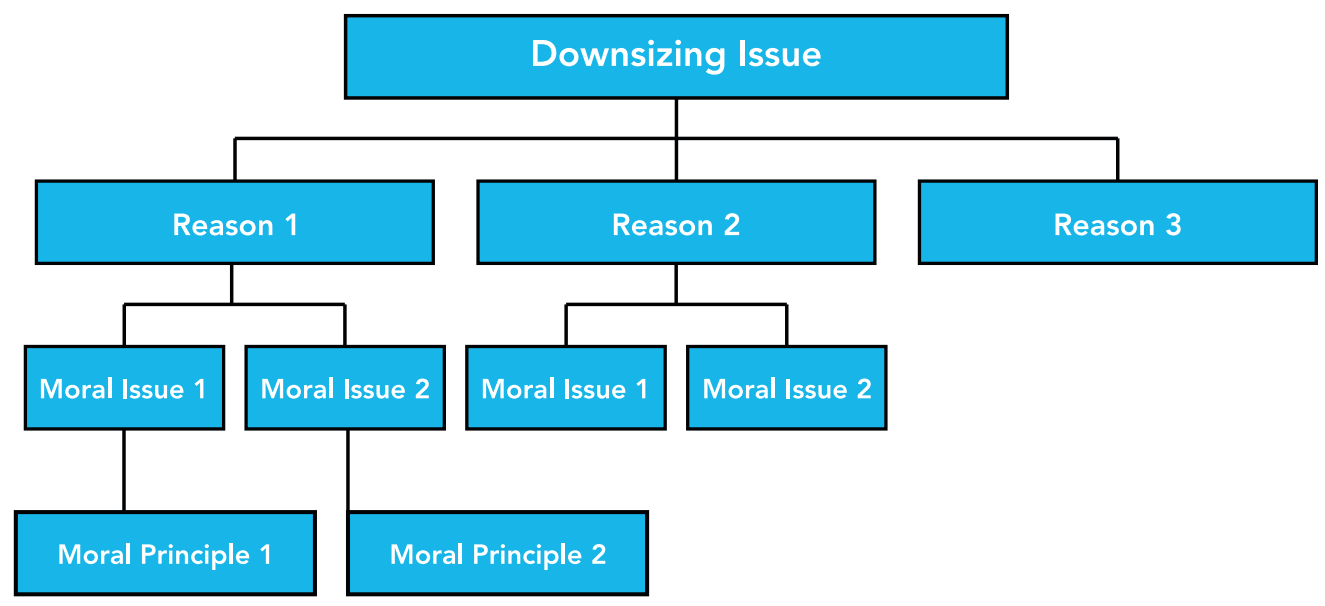

Diagram 1 A model of moral reasoning (adopted from Bruce Gahir)

In the third part - Downsizing in the theoretical framework - I will summarise my arguments from the main section, applying different approaches to ethical dilemmas, and reason about whether the particular reason for downsizing in Boeing Corp. is ethical in the light of a moral theory and why.

In the Conclusions, I will suggest which of the theories (or their combination) are best applicable in certain circumstances. 
Ethical theories exist to assist in the decision-making process and making the 'right' ethical choice among any other alternatives that may exist in certain circumstances. These decision-making tools adopted from philosophy are especially useful when two or more 'right' values are in conflict; this is often called ethical dilemmas.

Before I put the downsizing problematic in the context of various ethical theories, it is important to note that none of the approaches suggest the best solution. They just look at the issue from the multiple perspectives and can and usually do come to different conclusions. The theories are nevertheless helpful to analyse the ethical dilemmas carefully and comprehensively, and one is able to explain the decision-making process if required to do so.

I shall illustrate the ethics of corporate downsizing in the case study of Boeing Corporation, the world's largest aerospace company and manufacturer of jetliners and defense security systems. Boeing currently (April, 2012) employs 172,000 people across the United States and in 70 countries (Boeing employment table, 2012).

Case Study - Boeing layoffs 1971 er 1997 (a summary from the EIREconomics journal article 'Boeing layoffs usher in new phase of production collapse' by Richard Freeman, 1998):

The history of Boeing Corp. dates back to 1917, when founder William Boeing incorporates Pacific Aero Products Company. During the wartime Boeing's production was at its peak, manufacturing 16 airplanes every 24 hours. During late 1960s, however, Boeing experienced the slowdown, especially when the complex and costly project on SST aircraft was called off by the U.S Congress in 1971. The company was close to bankruptcy and this was when the first major staff reduction was announced. 43,200 employees were laid off; this represented 53.7\% of the total workforce in 1971! The second major workforce reduction took place during 1997-1998, when as much as 48,000 people were laid off due to the two major causes: cost-accountant of workforces after the merger with McDonnel Douglas and Asian recession that resulted in the cancellation of significant number of orders from Boeing.

\section{REASON 1: COST REDUCTION DUE TO THE RECESSION PERIODS, LEADING TO REDUCING LABOR COSTS.}

\section{MORAL ISSUE 1.1: EFFECTS ON STAKEHOLDERS: EMPLOYEES, SUPPLIERS \& LOCAL COMMUNITY}

1. Losses of jobs lead to loss of income and decreased standards of living. For families for which Boeing employment was the only income stream, financial consequences can be devastating.

2. Psychological effect: low self-esteem, depression, frustration, guilt, and other damaging emotions of former employees that affect also their families and friends.

3. According to Henkoff (1990), 74\% of senior managers in downsized companies said morale, trust, and productivity suffered after downsizing. Cole (1995) adds that personal relationships between employees and customers, customer loyalty, and common organisational culture are lost.

4. Local unemployment rate went up significantly in Seattle; highly skilled labor pool (e.g. machinists, engineers, etc.) had been laid off (Freeman, 1998).

5. Cuts in Boeing production create cascades of layoffs in related sectors of the economy, e.g. Northrop Grumman (military aircraft maker) laid off 1,100 workers in response to Boeing's layoffs in 1997, representing almost 17\% of their workforce (Freeman, 1998). 
Moral Principle 1.1: Organisations are socially responsible towards its employees to ensure the ' good' livelihood of people in the community, because it is a part of the society. By downsizing a large number of people, they fail to perform Corporate Social Responsibility from the ethical theory point of view. One of the approaches of CSR is normative stakeholder theory adapted from the Kantian capitalism approach to business ethics, the core principle of which is that stakeholders are to be treated as an ends, and not as a mere means of earning profits for shareholders. Therefore, the organisation has a duty to ensure the employment in the community, because it is the right thing to do, despite of some desired outcome.

Limitations: While organisations have duty towards employees, they are also responsible for their shareholders. The question is therefore: whose interests to serve first? Shareholders have risked their money in the investment in the organization; employees, on the other hand, have taken on different kinds of risk. Consequently, the right thing to do is to evaluate the involvement based on risk and balance the two.

\section{MORAL ISSUE 1.2: EFFECT ON BOEING CORPORATION.}

1. The layoffs in 1970 saved the company from bankruptcy.

2. The company was able to survive and revitalize after the recession in the aviation industry in 1970.

3. After the recession Boeing was able to gear up production, but had difficulties meeting the deadlines due to the lack of experienced workers. Boeing rehired many of them during 1972-74.

Moral Principle 1.2: Despite all of the negative effects on the company's stakeholders, thanks to downsizing, the Boeing Corporation was able to sustain its business activity. Unlike the Kantian approach, the Utilitarian view takes into account all possible consequences of the action, which the principle is ' the greatest good for the greatest number'. Should the company had kept its staff, it would have most probably gone bankrupt. In this case not 43,200 people would have lost their jobs, but all 80,500 workers who were employed by Boeing in 1970, and the effect on the community would have been twice, if not three times more devastating, not mentioning the fact that currently Boeing is the largest maker of airplanes supplying its jets to countries around the world, employing 171,660 people (Boeing employment table, 2012).

Limitations: Apart from the negative consequences on stakeholders listed above, there may be many others that have not been quantified, because it is impossible to oversee all of them. It is also not possible to assign the monetary value to calculate all the indentified costs and benefits, as well as it is not possible to claim that the company would have ceased to exist should it have not reduced its workforce. Therefore the statement that downsizing maximises welfare because it benefits the majority of population is hard to prove.

\section{REASON 2: REORGANISING AND RESTRUCTURING DUE TO THE MERGER WITH MCDONNEL DOUGLAS COMPANY, LEADING TO ELIMINATING JOBS.}

\section{MORAL ISSUE 2.1: EFFECT ON BOEING CORPORATION.}

1. By restructuring, Boeing became the largest commercial aerospace maker in the world and the second largest defense company, which helped them diversify their services, all through the cost of people working in both of the organisations.

Moral Principle 2.1: According to one of the formulations of Kant's Categorical Imperative, "act only on maxims which you can will to be universal laws of nature." In other words: does restructuring justify downsizing? Would a world where every company after mergers and acquisitions laid off duplicate workers 
be possible? Kant does not focus on the consequences here (which we know can be significant); rather he is suggesting a test on morality: if the very concept (downsizing after merger), when adopted as a principle by everyone is coherent, then it is morally permissible. The real life examples show that this is the common practice that most of the companies reduce their workforce after mergers and acquisitions (HP and Compaq, Procter er Gamble and Gillette, etc).

Limitations: The fact that downsizing became a common practice as a means of reducing workforce after mergers does not automatically make it a moral act. Employees do not participate in the merger/ acquisition decisions, yet they are affected above all. On the other hand, doing nothing about duplicate jobs would create more complications and chaos within the company, not mentioning the costs keeping the workers whose jobs has been taken over by someone else. This is where The Ethics of Care could be useful. The questions that should be asked are: since downsizing after merger is the last resort for businesses, does this action exhibit appropriate care for those employees who have been redundant? What kind of care has been provided (severance pay, help in finding another job, etc)?

\section{MORAL ISSUE 2.2: EFFECT ON EMPLOYEES (FORMER AND ' SURVIVORS’)}

1. Where duplicate jobs took place, the best performer was chosen.

Moral Principle 2.2: I have already stated that from the Utilitarian point of view, when the company is forced to cut costs in the recession periods, downsizing can be justified because it is more likely to provide greater good to greater number of people. In case of mergers, however, the company was not forced by external factors such as economic slowdown, and therefore redundancy of workforce is the company's internal strategy to increase the financial value for shareholders. Therefore, if we look at the downsizing after merger issue through the lenses of justice and fairness, then we can say that greater benefits for some do not justify injustices to others. According to which principles have the workers been eliminated? Downsizing can become a very delicate issue for the companies, for example, to avoid discrimination accusations (age, gender, race, etc.).

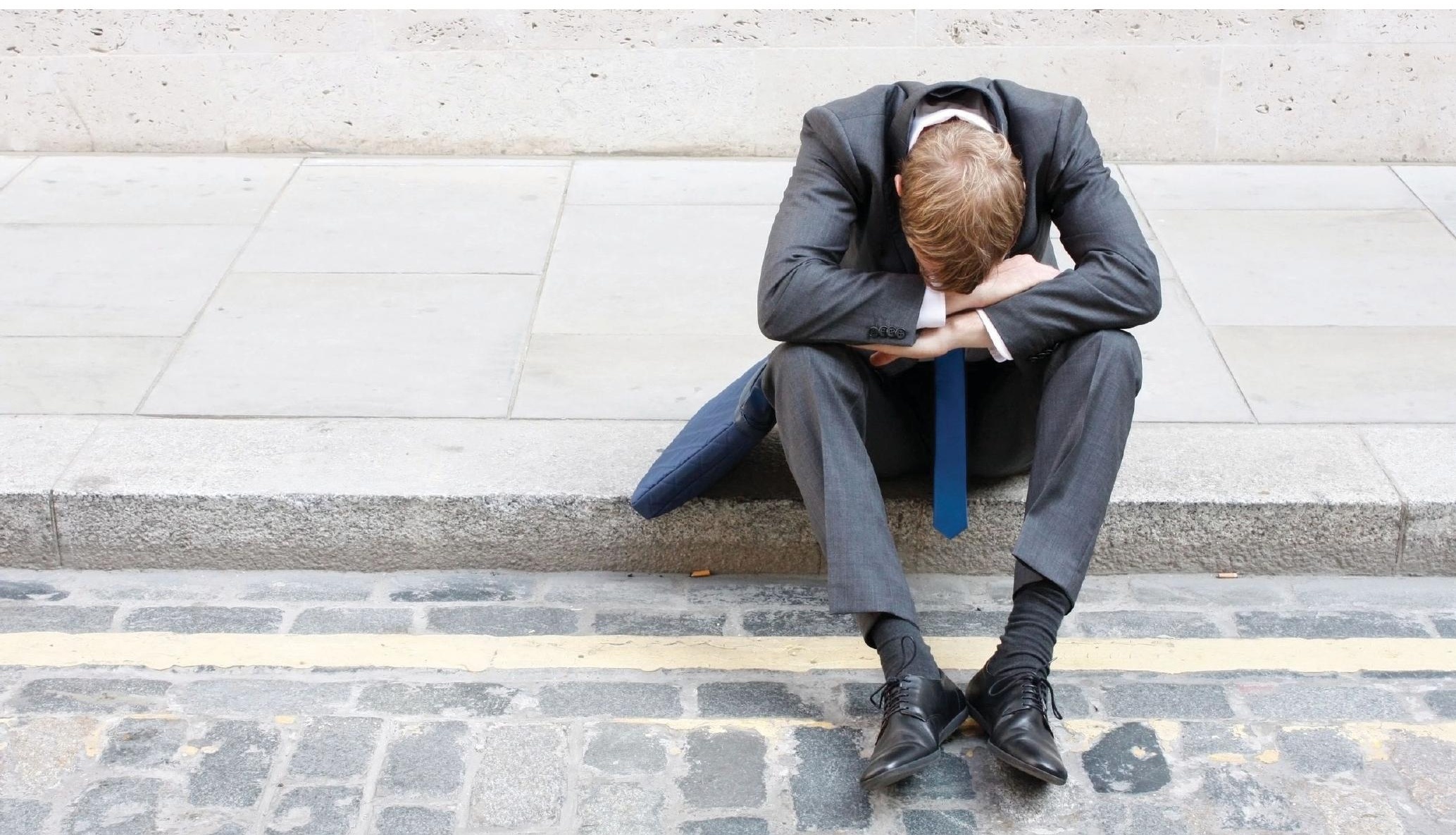




\section{DOWNSIZING IN THE THEORETICAL FRAMEWORK}

In the chosen business case scenario, the Boeing layoffs (1970 e 1997), I have identified two main reasons for downsizing, cost reduction due to the economic recession and the job elimination due to the merger. The list of reasons, however, is much more extensive than that, but the main motive behind all of the layoffs is cost reduction. I have, however, identified that cost cutting as an internal strategy can be either forced or planned.

In the first case scenario, organisations are forced to slow the production and cut costs due to the economic slowdowns. Another type of cost reduction can occur due to the management decision to increase financial value, reallocate resources, or change/stop the production of a particular type of product(s), and other internal reasons.

It is essential, in my opinion, to differentiate the motives, because the conclusions regarding the morality of the downsizing phenomenon based on the reasons can be made different.

\begin{tabular}{|c|c|}
\hline $\begin{array}{l}\text { COST CUTTING } \\
\text { RECESSION }\end{array}$ & $\begin{array}{l}\text { COST CUTTING } \\
\text { RESTRUCTURE \& MERGER }\end{array}$ \\
\hline $\begin{array}{l}\text { Downsizing is ethical according to the Utilitarian } \\
\text { approach, if in times of recession it is the least } \\
\text { harmful option. Comparing to the consequences of } \\
\text { bankruptcy, should Boeing have not reduced its work- } \\
\text { force, downsizing effect was less harmful. }\end{array}$ & $\begin{array}{l}\text { In this case 'greater benefits for greater number } \\
\text { of people' are much less obvious, because the exist- } \\
\text { ence of the company is not threatened (at least not on } \\
\text { the short-run). It seems that greater benefits are only } \\
\text { experienced by the company executives and the com- } \\
\text { pany's shareholders. Reducing the costs while becom- } \\
\text { ing the largest commercial airplanes maker can also put } \\
\text { great pressure on smaller companies, as well as barriers } \\
\text { to entry for new companies. }\end{array}$ \\
\hline $\begin{array}{l}\text { Downsizing is like a sword with two ends; one end rep- } \\
\text { resents employees and the other one the sharehold- } \\
\text { ers. According to the Kantian theory, if we focus } \\
\text { solely on shareholders, we treat employees as means } \\
\text { (means of reducing costs), but not as ends. Vice versa, if } \\
\text { we serve only employees' interest we treat them as ends, } \\
\text { but we treat shareholders as means (means of having an } \\
\text { investment). Therefore, if downsizing is driven by } \\
\text { the external factors (such as recession) and the ac- } \\
\text { tion is based on the balance of interests, down- } \\
\text { sizing can be said to be ethical, if this is the reason } \\
\text { that everyone could act upon taken into account the } \\
\text { balance of interest, and everyone be willing to have all } \\
\text { others use this reason with this condition as well. }\end{array}$ & $\begin{array}{l}\text { According to Kant's Categorical Imperative, when } \\
\text { applying the Universal Law in maxim (rule) formu- } \\
\text { lation, there can be two kinds of contradictions: with } \\
\text { fundamental human desires and when the very con- } \\
\text { cept, when adopted as a universe principle, is incoher- } \\
\text { ent. The formulation such as: 'organisations should } \\
\text { downsize in order to eliminate duplicate jobs } \\
\text { that have occurred due to the merger/acquisi- } \\
\text { tions' does not contradict any of the two, and } \\
\text { therefore it is morally permissible. }\end{array}$ \\
\hline $\begin{array}{l}\text { Unlike the utilitarianism, where an action is understood } \\
\text { in terms of the consequences, Kant views an action } \\
\text { in terms of intentions. Intentions behind downsiz- } \\
\text { ing in times of recession are to save the company from } \\
\text { bankruptcy, therefore saving more people from losing } \\
\text { the jobs. Simplifying: the intention is to treat people } \\
\text { as ends. }\end{array}$ & $\begin{array}{l}\text { In case of mergers, the intention is to restructure the } \\
\text { organisation in the most efficient way, and that is to re- } \\
\text { duce workforce and save costs. Simplifying: the inten- } \\
\text { tion is to treat people as means. }\end{array}$ \\
\hline
\end{tabular}




\section{CONCLUSIONS}

There is no universal truth about the ethics of downsizing; no theoretical framework is able to help us justify the morality of the notion in full certainty. Being guided, for example, solely by the Utilitarian approach, we can come to the conclusion that downsizing is not unethical, because consequently the benefits are greater than the damage. Kant's supporters would disagree, saying that consequences do not justify the action itself, and that downsizing is unethical, because it contradicts the very desire of people to have a source of income. Both deontological and teleological approaches are categorical in their own way. But both of them are applicable in a given scenario to a certain extent, and this is because each scenario of downsizing is individual, as well as the motives and the circumstances surrounding it, and this is why by combining the two, by creating some sort of a hybrid of ethical theories, we may be able to broaden our mind about the issue. They do not necessarily have to contradict one another, but rather fill each other's gaps.

For example, it makes a lot of sense to suggest that downsizing is the least harmful option when the slowdown of economy forces companies to reduce their costs to stay in the market. But is this the last resort for a business, or rather it turns to downsizing as one of the first options? In other words, were people treated as ends, rather than means? What are the intentions of the company's management? Do they intend to rehire the staff after the situation will have been stabilised?

Another example such as the reorganisation, where applying the Utilitarian approach does not give us a clear understanding of the costs and benefits, we may create the formulation of maxim such as 'Organisations should downsize in order to eliminate duplicate jobs that have occurred due to the merger/acquisitions', which does not contradict once applied universally and is therefore rationale. However, each case should be examined separately. Companies should evaluate the consequences: whether by downsizing they are not contributing to the local unemployment rate, they should also take into the account the effects it is going to have on the remaining employees and the organisational culture as a whole. 


\section{REFERENCES}

Atwood, J., Coke E., Cooper, C., and Loria K. (1996) Has downsizing gone too far? University of North Florida, Jacksonville, Florida, USA. Available at: <http://faculty.css.edu/dswenson/web/downsize.html> [Accessed 19 May 2012].

Bowie, N.E. (n.d.) Business Ethics and Normative Theories. [pdf] Available at: <http://www.blackwellpublishing.com/ content/BPL_Images/Content_store/Sample_chapter/1405101024\%5C001.pdf> [Accessed 24 May 2012].

Carriga, E. and Mele, D. (n.d.) Corporate Social Responsibility Theories: Mapping the Territory. [pdf] Available at: <http:// www.cs.unitn.it/ andreaus/bs1112/garriga_mel\%C3\%A9.pdf> [Accessed 20 May].

Field, R. (1999) A Practical Guide to Ethical Theory, Northwest Missouri State University. Available at: <http:/ / catpages. nwmissouri.edu/m/rfield/274guide/title.htm> [Accessed 20 May 2012].

Freeman, R. (1998) ' Boeing layoffs usher in new phase of production collapse', EIR, 25(50) [Online]. Available at: <https://www.larouchepub.com/eiw/public/1998/eirv25n50-19981218/eirv25n50-19981218_004-boeing_ layoffs_usher_in_new_phas.pdf> [Accessed 19 May 2012].

IBS Center for Management Research (2002) Employee Downsizing. Available at: <http://www.icmrindia.org/free\%20 resources/casestudies/employee-downsizing-3.htm> [Accessed 19 May 2012].

Prague College/Teesside University (2012) B.A. - Business Ethics and Corporate Governance. Readings and Case Studies, Prague College, Prague.

Project on Government Oversight (1997) Boeing McDonnell Douglas: A Merger Too Far. Available at: <http:/ /www. pogo.org/pogofiles/alerts/national-security/ns-dcm-19970101.html> [Accessed 25 May 2012].

The Boeing Company (2012) The Boeing Company. Available at: <http://www.boeing.com/> [Accessed 19 May 2012].

Stanford Encyclopedia of Philosophy (2008) Kant's Moral Phylosophy. Available at: <http:/ / plato.stanford.edu/ entries/kant-moral/\#ForUniLawNat> [Accessed 26 May 2012]. 